\title{
IDENTIFIKASI SENYAWA KIMIA PADA EKSTRAK BASA BUAH LEUNCA (Solanum nigrum Linn) DENGAN TEKNIK KHROMATOGRAFI
}

\author{
Mamay Maslahat*, Dani Ramdani dan RTM Sutamihardja \\ Universitas Nusa Bangsa \\ Jl. K. H. Sholeh Iskandar, Cimanggu, Tanah Sareal-Bogor 16166 \\ *e-mail : maykulsum@yahoo.co.id
}

\begin{abstract}
Identification of Chemical Compounds at the Leuncas Fruits Base Extracts with Chromatography Methodes

By. Mamay Maslahat, Dani Ramdani and RTM Sutamihardja
\end{abstract}

\begin{abstract}
Secondary methabolites contain in the plant was a alkaloids, flavonoids, terphenoids, steroids that use for medicinal, biopestiside, etc. Taksonomy principle of Leunca (Solanum nigrum Linn) is clasified to Solanaceae family, and prediction contains alkaloids. The leunca fruits base extracts qualitative tested with Dragendorf reagents and indetified with thin layer chromatography (TLC), coloumn chromatography (CC), and gass chromatography mass-spectra (GC-MS). Optimation of eluens as mobile fase for TLC and CC used three eluens, there are methanol: $\mathrm{NH}_{4} \mathrm{OH}$ (200:3), chloroform:methanol (17:3), and chloroform:ethanol (4:1). Dragendorf test showed extract contains alkaloids compounds. Eluens optimum was chloroform:methanol (17:3) with trhree fraction ,and GC-MS identification showed that extract contains chemical compounds as carbocilic acid, thiourea, nicotinic acid, and glicerol.
\end{abstract}

Keyword s: Alkaloids compounds, leunca, chromatography

\begin{abstract}
ABSTRAK
Metabolit sekunder yang terkandung pada tanaman dapat berupa senyawaan kimia alkaloid, flavonoid, terpenoid, dan steroid. Senyawaan kimia ini dapat berfungsi sebagai obat, biopestisida, dan sebagainya. Leunca (Solanum nigrum Linn) berdasarkan ilmu taksonomi diklasifikasikan ke dalam famili Solanaceae (labu-labuan), dan diduga banyak mengandung senyawaan alkaloid yang berkhasiat sebagai obat. Ekstrak basa buah lenca diuji dengan pereaksi Draggendorf dan diidentifikasi dengan menggunakan teknik kromatografi lapis tipis (KLT), kromatografi kolom, dan instrumen kromatografi gas-spektra massa (GC-MS). Optimasi eluen sebagai fase gerak pada KLT dan kromatografi kolom dilakukan terhadap 3 jenis dan komposisi eluen yang berbeda yaitu Metanol : $\mathrm{NH}_{4} \mathrm{OH}$ (200:3), Kloroform:Metanol (17:3), dan Kloroform:Etanol (4:1). Hasil uji Dragendorf mengindikasikan bahwa ekstrak basa buah lenca mengandung senyawaan alkaloid. Hasil optimasi eluen menunjukkan bahwa eluen yang optimum adalah Kloroform:Metanol (17:3) dengan memberikan 3 fraksi pemisahan. Nilai Rf ketiga fraksi tersebut adalah 0,$21 ; 0,31$ dan 0,60. Berdasarkan analisis dengan GC-MS diketahui bahwa ekstrak basa buah lenca mengandung senyawaan kimia karboksilat, tiourea, asam nikotinat, dan gliserol.
\end{abstract}

Kata kunci : Senyawa alkaloid, leunca, kromatografi

\section{PENDAHULUAN}

Leunca dalam ilmu taksonomi dikenal sebagai Solanum nigrum Linn dan digolongkan dalam keluarga Solanaceae (labu-labuan). Kandungan kimia yang terkandung dalam tanaman leunca (bagian daun) diketahui antara lain Glikoalkaloid solanin, Solasonin, Solamargin, Solasodin, Solanidin, Diosgenin, Tigogenin, Atropin, Saponin, Zat samak,
Minyak lemak, Kalsium, Fosfor, Zat besi, Vitamin A dan C (Anonim, 2006).

Metabolit sekunder (senyawa aktif) dapat diisolasi, difraksinasi dan kemudian diidentifikasi menggunakan metode kromatografi (Gritter, 1996). Metabolit sekunder ini diketahui terkandung pada bagian daunnya, sementara informasi mengenai metabolit sekunder yang terkandung dalam buah leunca masih terbatas. Hal ini menjadikan 
perlunya identifikasi secara ilmiah akan kandungan metabolit sekunder, khususnya senyawa alkaloid dalam buah leunca.

\section{METODE PENELITIAN}

\section{Bahan dan Alat}

$$
\begin{aligned}
& \text { Bahan - bahan yang dipergunakan } \\
& \text { adalah buah leunca muda, metanol, } \\
& \text { aquades, asam sulfat, Pereaksi } \\
& \text { Dragendorff, kloroform, dan amonia. } \\
& \text { Peralatan yang digunakan terdiri dari } \\
& \text { peralatan gelas, kertas saring, kertas pH, } \\
& \text { alumunium foil, penangas air, pelat } \\
& \text { Kromatografi Lapis Tipis (KLT) dengan } \\
& \text { adsorben silikagel, chamber kromatografi, } \\
& \text { lampu UV scanner, kolom kromatografi, } \\
& \text { neraca analitik dan Gas Chromatography } \\
& \text { Mass Spectrometry (GC-MS) dengan } \\
& \text { spesifikasi sebagai berikut: }
\end{aligned}
$$

$\begin{array}{lll}\text { Merk } & : \text { J\&W Scientific } \\ \text { Kolom } & : \text { Polysiloxane } \\ & \begin{array}{l}\text { polymers; panjang 30 } \\ \mathrm{m} \text { dan diameter } 0,32 \\ \mathrm{~mm} .\end{array} \\ \text { Suhu } & :-60^{\circ} \mathrm{C} \text { sampai } 325^{\circ} \mathrm{C} \\ \text { Waktu alir } & : & 25 \text { menit } \\ \text { Gas pembawa } & : \text { Helium }(\mathrm{He})\end{array}$

\section{Cara Kerja}

\section{Ekstraksi}

Buah leunca muda sebanyak $200 \mathrm{~g}$ dicacah dan dihomogenkan dalam Metanol: $\mathrm{H}_{2} \mathrm{O}$ (4:1) selama 5 menit. Campuran disaring, filtrat yang dihasilkan diuapkan pada suhu $40^{\circ} \mathrm{C}$ sampai volume sepersepuluh dari volume awal. Campuran diasamkan dengan $\mathrm{H}_{2} \mathrm{SO}_{4} \quad 1 \mathrm{M}, \quad$ kemudian diekstrak dengan kloroform sebanyak 3 kali. Setelah terbentuk dua lapisan, pada lapisan air-asam ditambahkan $\mathrm{NH}_{4} \mathrm{OH}$ hingga $\mathrm{pH}$ larutan 10. Larutan ini diekstraksi dengan campuran kloroform:metanol (1:3) sebanyak 2 kali dan diteruskan dengan kloroform sebanyak 1 kali. Ekstrak kloroform-metanol dipisahkan sebagai ekstrak basa yang mengandung kebanyakan senyawa alkaloid. Ekstrak ini diuapkan untuk pemekatan.

2. Pemeriksaan Alkaloid

Ekstrak basa buah leunca diteteskan beberapa tetes pada kertas saring dan disemprot dengan pereaksi Dragendorff. Pembentukan warna merah atau jingga pada kertas menunjukkan adanya senyawa alkaloid.

3. Optimasi Fasa Gerak

Ekstrak leunca ditotolkan plat KLT dan dieluasi dengan variasi fasa gerak yaitu Metanol : $\mathrm{NH}_{4} \mathrm{OH}(200$ : 3), Kloroform : Metanol (3: 17), dan Kloroform : Etanol (4: 1) (Harborne, 1987; Ningsih, 2006). Fasa gerak yang optimum dalam memisahkan ekstrak alkaloid digunakan sebagai fasa gerak pada fraksinasi dengan kromatografi kolom.

4. Fraksinasi dengan Kromatografi Kolom

Ekstrak leunca sebanyak $10-15 \mathrm{ml}$ dimasukan ke dalam kolom yang berisi fasa diam silikagel 60 . Fasa gerak dialirkan ke dalam kolom kromatografi untuk memisahkan sampel menjadi beberapa fraksi. Fraksi-fraksi yang dihasilkan ditampung berdasarkan volume dalam tabung reaksi, masing masing tabung berisi $5 \mathrm{ml}$ fraksi.

5. Pemeriksaan Kromatografi Lapis Tipis (KLT)

Setiap fraksi yang dihasilkan ditotolkan pada plat KLT dan dielusi dengan fasa gerak optimum.

6. Identifikasi Senyawa Kimia

Fraksi-fraksi yang menunjukkan adanya spot noda pada KLT diidentifikasi dengan Gas Chromatography Mass Spectrometry (GCMS). 


\section{HASIL DAN PEMBAHASAN}

\section{Ekstraksi}

Buah leunca segar untuk penelitian ini diperoleh dari pasar tradisional di Bogor. Buah leunca yang digunakan merupakan buah leunca muda segar yang dicirikan dengan warna buah hijau. Dua ratus gram buah leunca muda segar yang telah dicacah dan diekstraksi dengan metode ekstraksi Harborne 1987 menghasilkan ekstrak basa sebanyak $30 \mathrm{ml}$ berwarna kuning kehijauan. Keberhasilan ekstraksi dengan alkohol untuk mengisolasi senyawa (termasuk alkaloid) dari tumbuhan berkaitan langsung dengan seberapa jauh klorofil tertarik oleh pelarut tersebut (Harborne, 1987). Untuk selanjutnya alkaloid dipisahkan dari klorofil dan senyawa lain dengan reaksi penggaraman menggunakan asam encer, sehingga alkaloid dalam bentuk garam tertahan pada lapisan air (polar).

\section{Pemeriksaan Alkaloid}

Pemeriksaan awal kandungan senyawa alkaloid dalam ekstrak basa dengan menggunakan pereaksi Dragendorff menunjukkan hasil uji positif yang ditunjukkan dengan timbulnya warna jingga pada kertas yang telah diteteskan ekstrak basa.

Adanya kandungan alkaloid dalam suatu cuplikan ditunjukkan dari adanya reaksi antara alkaloid dengan kompleks kaliumtetraiodobismutat (Goddel, 2005), seperti reaksi di bawah ini :

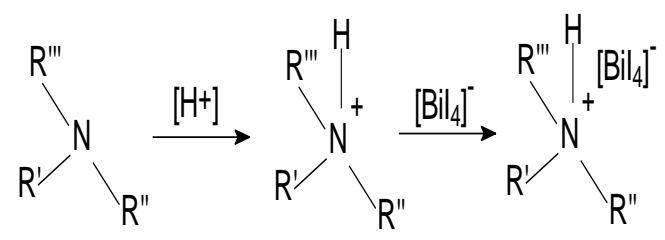

Gambar 1. Mekanisme Reaksi Alkaloid dengan Pereaksi Dragendorff

\section{Identifikasi Senyawa Kimia}

\section{Optimasi fasa gerak dengan Kromatografi Lapis Tipis (KLT)}

Ekstrak basa dianalisis dengan KLT menggunakan fasa gerak yang bervariasi diantaranya, Metanol : $\mathrm{NH}_{4} \mathrm{OH}$ (200:3), Kloroform : Metanol (17: 3), dan Kloroform : Etanol (4 : 1). Untuk mengidentifikasi hasil pemisahan digunakan lampu UV Scanner. Berikut ini merupakan gambar pemisahan ekstrak basa menggunakan fasa gerak Metanol : $\mathrm{NH}_{4} \mathrm{OH}$ (200:3) dengan tiga kali pengulangan.

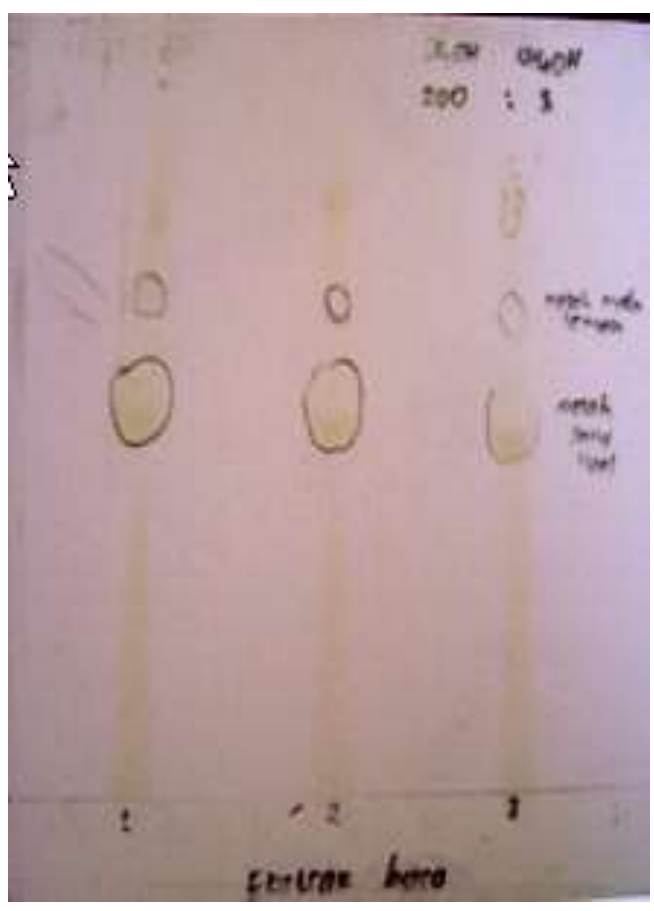

Gambar 2. Pemisahan Ekstrak Basa dengan Fasa Gerak Metanol : $\mathrm{NH}_{4} \mathrm{OH}(200: 3)$

Spot noda yang terpisah pada Gambar 2 memiliki nilai Rf 0,49 dan 0,60 . Berdasarkan jenis fasa diam dan fasa gerak yang digunakan maka spot noda dengan nilai $\mathrm{Rf} 0,49$ diduga merupakan senyawa alkaloid solanin, sedangkan spot noda dengan nilai Rf 0,60 diduga merupakan senyawa alkaloid nikotin (Harborne, 1987). 
Fasa gerak lain yang digunakan untuk optimasi pemisahan adalah Kloroform : Metanol (17 : 3). Hasil pemisahan menunjukan adanya tiga spot noda dengan nilai $\operatorname{Rf} 0,21 ; 0,31$; dan 0,60 .

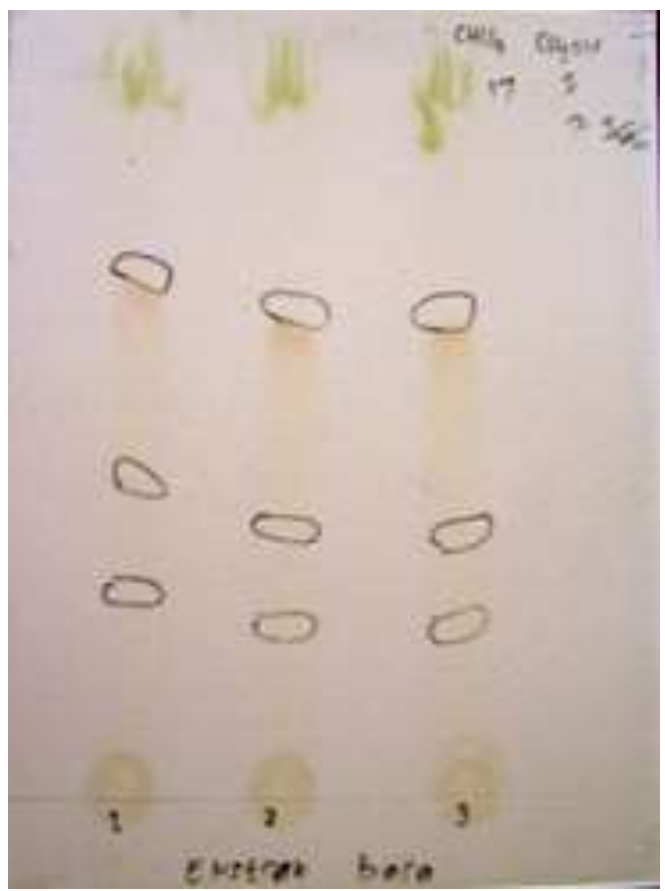

Gambar 3. Pemisahan Ekstrak Basa dengan Fasa Gerak Kloroform : Metanol (17:3)

Fasa gerak Kloroform:Metanol (17:3) merupakan fasa gerak yang digunakan untuk memisahkan senyawa alkaloid khusus yang terdapat pada tembakau (Harborne, 1987). Fasa gerak ini dipilih pula untuk memisahkan senyawa alkaloid leunca dengan asumsi leunca dan tembakau termasuk suku tumbuhan solanaceace.

Fasa gerak berikutnya untuk pemisahan ekstrak basa dengan metode KLT adalah Kloroform : Etanol (4:1). Fasa gerak ini merupkan fasa gerak untuk zat pahit pada tumbuhan (Anonim, 2005b). Rasa pahit pada daun atau buah segar mengindikasikan adanya kandungan alkaloid (Harborne, 1987).Adapun hasil pemisahan dengan fasa gerak ini terlihat pada Gambar 4. Hasil pemisahan menunjukkan adanya dua spot noda yang terpisahkan dari ekstrak basa. Spot noda tesebut memiliki nilai Rf 0,33 dan 0,52.

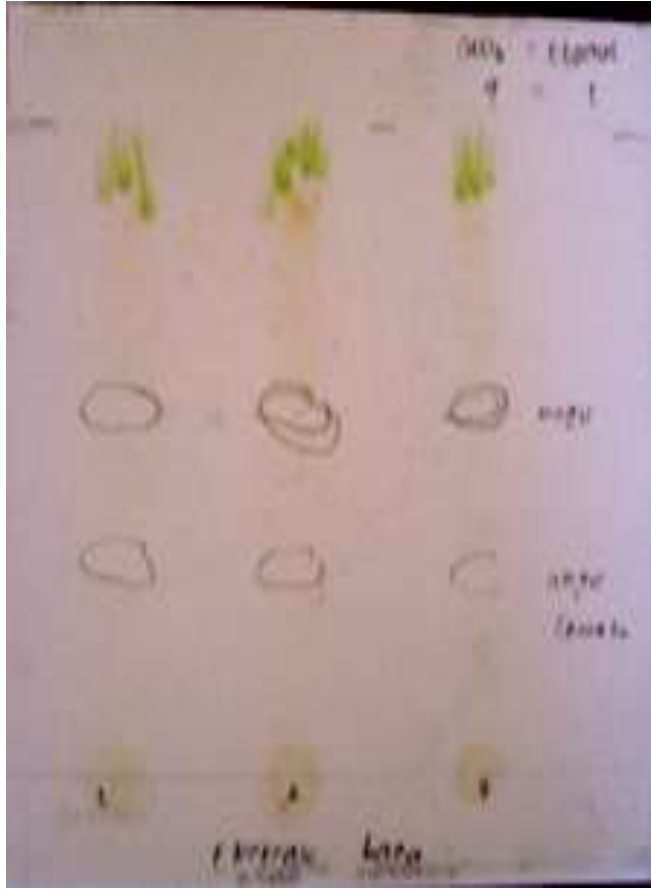

$\begin{array}{lllr}\text { Gambar 4. } & \begin{array}{l}\text { Pemisahan } \\ \text { dengan }\end{array} & \text { Ekstrak } & \text { Basa } \\ & \text { Kloroform : Etanol }(4: 1)\end{array}$

Hasil KLT dari berbagai fasa gerak yang digunakan disajikan pada Tabel 1.

Tabel 1 menunjukan bahwa fasa gerak Kloroform : Metanol (17 : 3) merupakan fasa gerak yang memberikan pemisahan optimum dengan 3 spot noda hasil pemisahan. Fasa gerak Kloroform:Metanol (17 : 3) ini yang selanjutnya digunakan sebagai fasa gerak dalam fraksinasi dengan kromatografi kolom.

\section{Fraksinasi dengan kromatografi kolom}

Ekstrak basa yang diperoleh dimurnikan dengan cara difraksinasi menggunakan fasa gerak optimum Kloroform:Metanol (17 : 3). Ekstrak difraksinasi menggunakan kromatografi kolom dengan panjang $30 \mathrm{~cm}$ dan diameter $12 \mathrm{~mm}$. Fraksi yang diperoleh ditampung dalam tabung reaksi, tiap tiap tabung berisi $5 \mathrm{ml}$ eluat. Ekstrak basa yang masuk ke dalam kromatografi kolom sebanyak $15 \mathrm{ml}$ dengan fasa gerak sebanyak $20 \mathrm{ml}$ sehingga diperoleh sekitar 
8 fraksi. Secara fisik setiap fraksi memberikan warna larutan yang sama.

\section{Pemeriksaan KLT Hasil Pemisahan Kromatografi Kolom}

Setiap fraksi yang diperoleh selanjutnya diuji kembali secara KLT dengan menggunakan fasa gerak
Kloroform : Metanol (17 : 3). Analisis KLT fraksi 7 menghasilkan bercak tunggal dengan nilai $\mathrm{Rf} 0,62$ sedangkan pada fraksi 8 terdapat 2 bercak dengan nilai $\mathrm{Rf}$ masing-masing 0,29 dan 0,62 . Fraksi yang menunjukkan adanya spot noda selanjunya dianalisis dengan Gas Chromatography Mass Spectrometry (GCMS).

Tabel 1. Hasil Kromatografi Lapis Tipis Ekstrak Basa Buah Leunca Muda

\begin{tabular}{|c|c|c|c|c|c|}
\hline \multirow{2}{*}{ Fasa gerak } & \multicolumn{2}{|c|}{ Jarak Alir $(\mathrm{cm})$} & \multicolumn{2}{|r|}{ Warna pada UV } & \multirow{2}{*}{$\mathrm{Rf}$} \\
\hline & Pelarut & Noda & $254 \mathrm{~nm}$ & $366 \mathrm{~nm}$ & \\
\hline \multirow{2}{*}{ A } & \multirow{2}{*}{8,5} & 4,2 & - & Merah muda lemah & 0,49 \\
\hline & & 5,1 & & Merah muda kuat & 0,60 \\
\hline \multirow{3}{*}{ B } & \multirow{3}{*}{8,6} & 1,8 & - & Kuning kehijauan & 0,21 \\
\hline & & 2,7 & & Ungu & 0,31 \\
\hline & & 5,2 & & Kuning kehijauan & 0,60 \\
\hline \multirow{2}{*}{$\mathrm{C}$} & \multirow{2}{*}{7,0} & 2,3 & - & Ungu & 0,33 \\
\hline & & 3,7 & & Ungu lemah & 0,52 \\
\hline
\end{tabular}

Keterangan : $\quad A$ : Metanol : $\mathrm{NH}_{4} \mathrm{OH}(200: 3)$

B : Kloroform : Metanol (17:3)

C : Kloroform : Etanol (4:1)

Tabel 2. Hasil Analisis Ekstrak Basa dengan Gas Chromatography Mass Spectrometry

\begin{tabular}{cll}
\hline No. & Retention time (menit) & \multicolumn{1}{c}{ Senyawa kimia } \\
\hline 1. & 0,923 & Etanol \\
2. & 1,071 & Kloroform \\
3. & 1,397 & Asetaldehid \\
4. & 1,643 & Asam Butanoat, Asam Pentanoat \\
5. & 1,790 & Asam Butanoat \\
6. & 2,598 & Asam Butanoat \\
7. & 2,981 & Propanedioic acid \\
8. & 3,815 & Tiourea \\
9. & 4,477 & Benzen asetaldehid, Oxirane \\
10. & 5,830 & Metil nikotinat \\
11. & 7,066 & Asam Heksanoat \\
12. & 8,693 & Gliserol \\
\hline
\end{tabular}




\section{Identifikasi Fraksi dan Ekstrak Basa dengan Gas Chromatography Mass Spectrometry (GCMS)}

\section{a. Analisis GCMS Hasil Fraksinasi Kromatografi Kolom}

Hasil analisis dengan Gas Chromatography Mass Spectrometry (GCMS) untuk fraksi 7 menunjukkan adanya tiga puncak yaitu pada retention time 2,580 menit; 3,771 menit dan 17,339 menit. Berdasarkan informasi database, diketahui puncak pada retention time 2,580 menit merupakan asam butirat sementara puncak pada retention time 3,771 menit merupakan asam pentanoat dan puncak pada retention time 17,339 menit diketahui sebagai asam stearat atau asam oktadekanoat. Ketiga senyawa ini merupakan asam karboksilat. Rumus ketiga senyawa tersebut disajikan pada Gambar 5.

Hasil analisis GCMS untuk fraksi 8 menunjukkan adanya satu puncak yaitu pada retention time 9,163 menit. Berdasarkan database, diketahui puncak pada retention time 9,163 menit merupakan Butanedioic acid atau asam Suksinat.

\section{b. Analisis GCMS Ekstrak Basa Sebelum Fraksinasi}

Analisis GC-MS untuk kedua fraksi tidak menunjukkan adanya kandungan alkaloid, maka untuk lebih meyakinkan hasil pembacaan ini dilakukan juga pembacaan terhadap ekstrak basa sebelum dilakukan fraksinasi. Hasilnya terdapat 12 puncak, disajikan pada Tabel 2.

Diantara senyawa yang diperoleh, terdapat Metil nikotinat yang merupakan vitamin $\mathrm{B}_{3}$ atau biasa disebut niasin.

\section{KESIMPULAN}

Berdasarkan uji dengan pereaksi Dragendorff, ekstrak basa buah leunca mengandung senyawaan alkaloid. Hasil optimasi eluen menunjukkan bahwa eluen yang optimum adalah Kloroform:Metanol
Struktur senyawa kimia niasin disajikan pada Gambar 6.

Asam nikotinat sendiri merupakan derivat asam karboksilat dari piridin. Niasin aktif merupakan komponen penting dalam lintasan metabolik yang melibatkan metabolisme karbohidrat, lipid, serta asam amino (Hawab, 2006).

Telah disebutkan bahwa alkaloid khas pada suku tumbuhan Solanaceae adalah Solanin. Hasil penelitian menunjukkan tidak teridentifikasinya senyawa alkaloid Solanin dalam ekstrak basa buah leunca. Hal ini mungkin dikarenakan buah leunca yang diekstraksi masih muda sehingga alkaloid solanin belum sempuna disintesis dalam sistem metabolisme tumbuhan tersebut. Selain itu, penggunaan jenis dan komposisi fasa gerak yang belum tepat untuk analisis Solanin dengan metode Kromatografi Lapis Tipis (KLT) dan Kromatografi Kolom.

$\mathrm{H}_{3} \mathrm{C}-\mathrm{CH}_{2}-\mathrm{CH}_{2}-\mathrm{COOH}$

Asam Butirat

$\mathrm{H}_{3} \mathrm{C}-\mathrm{CH}_{2}-\mathrm{CH}_{2}-\mathrm{CH}_{2}-\mathrm{COOH}$

Asam Pentanoat

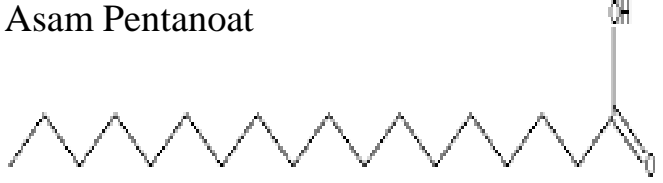

Asam Stearat

Gambar 5. Senyawa Kimia yang Terkandung Pada Fraksi 7 dan 8

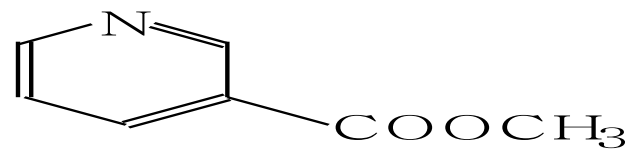

Gambar 6. Rumus Kimia Metil nikotinat

(17 : 3) dengan memberikan 3 fraksi pemisahan. Nilai Rf ketiga fraksi tersebut adalah 0,$21 ; 0,31$ dan 0,60. Berdasarkan analisis dengan GC-MS diketahui bahwa ekstrak basa buah lenca mengandung senyawaan kimia karboksilat, tiourea, asam nikotinat, dan gliserol. 


\section{DAFTAR PUSTAKA}

Anonim, 2005a. Gas Chromatography Mass Spectrometry. http://www.infolabonline.com/v1/index.php?infola $\mathrm{b}=$ detail\&detail $=125$, diakses tanggal 12 maret 2007.

Anonim, 2005b. Pusat Penelitian Obat Tradisional.

http://72.14.235.104/search?q=c ache:HIXa6qfHu4kJ:Ippm.wim a.ac.id/ppot/ABSTRAK-PENPPOT-WEBmikro.html+kloroform:etanol++ alkaloid\&hl=id\&ct=clnk\&cd= $\underline{1 \& g \mathrm{l}=\mathrm{id},}$ diakses tanggal 6 maret 2007.

Anonim, 2006. Leunca. http://www. ningharmanto.com/in-to/ leunca.htm, diakses tanggal 16 maret 2007.

Anonim, 2007. Solanum nigrum. http://en.wikipedia.org/wiki/Sol anine, diakses tanggal 28 April 2007.

Day, R. A. dan A. L. Underwood. 1989. Analisis Kimia Kuantitatif. Edisi V. Penerbit Erlangga. Jakarta.

Goddel, Bjorne B. 2005. Chromotropsaure Reaktion, Liebermann-Burchard

Reaktion, Nacweise mit Dragendorrf Reagenz. http://www.uni-saarland.de/ student/fspharma/downloads/fil es/seminare/eab/ws_05/Chromo tropsaeure\%20LiebermannBurchard\%20Dragendorff.pdf, diakses tanggal 23 Juli 2007.
Gritter, R. J., J. M. Bobitt. dan A. E. Schwarting., 1996. Pengantar Kromatografi, ITB. Bandung.

Harborne, J. B. 1987. Metode Fitokimia. Penerbit ITB. Bandung.

Hawab, H. M. 2006. Biokimia Umum. Universitas Nusa Bangsa. Bogor.

Heyne, K. 1987. Tumbuhan Berguna Indonesia III. Badan Penelitian dan Pengembangan Kehutanan, Departemen Kehutanan. Jakarta.

Merck \& Co., Inc. The Merck Index. $11^{\text {th }}$ edition. Editor: Susan Budavari. New York. USA.

Minarti. 2004. Isolasi dan Identifikasi Senyawa Bioaktivitas Alkaloida dari Daun Johar (Cassia siamea Lmk). Skripsi. Universitas Nusa Bangsa. Bogor.

Ningsih, D. R., Warsinah, dan Suwandri. 2006. Fraksinasi Ekstrak Metanol Kulit Batang Rhizophora mucronata dan Uji Daya Hambatnya terhadap Bakteri Eschericia coli. Jurnal Ilmiah Molekul. Vol. 1. No. 1. Jurusan Kimia FMIPA. Universitas Sudirman. Purwokerto.

Voigt, R. 1984. Buku Pelajaran Teknologi Farmasi. Universitas Gadjah Mada. Yogyakarta. Sumber internet.

Yusuf, Gunawan. 2005. Leunca, Bisa Jinakkan Kanker. http://www.mail-archive.com/ urangsunda@yahoogroups.com/ ms926223.html, diakses pada tanggal 9 Agustus 2007. 